Canadian

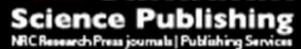

Canadian Journal of Forest Research Revue canadienne de recherche forestière

\title{
Heterogeneity in Attitudes Underlying Preferences for Genomic Technology Producing Hybrid Poplars on Public \\ Land
}

\begin{tabular}{|r|l|}
\hline Journal: & Canadian Journal of Forest Research \\
\hline Manuscript ID & cjfr-2017-0293.R3 \\
\hline Manuscript Type: & Article \\
\hline Complete List of Authors: & $\begin{array}{l}\text { Maruta, Admasu; University of South Australia, School of Commerce } \\
\text { Boxall, Peter; University of ALberta, REES } \\
\text { Mohapatra, Sandeep; University of ALberta, REES }\end{array}$ \\
\hline $\begin{array}{r}\text { Keyword: } \\
\text { Is the invited manuscript for } \\
\text { consideration in a Special } \\
\text { Issue? : }\end{array}$ & $\begin{array}{l}\text { Genomic Technology, Preferences Heterogeneity, Hybrid Poplars, Cluster } \\
\text { Analysis, Probit Model }\end{array}$ \\
\hline & \\
\hline
\end{tabular}

SCHOLARONE ${ }^{m}$

Manuscripts 
Title:

2

3 Heterogeneity in Attitudes Underlying Preferences for Genomic Technology

$4 \quad$ Producing Hybrid Poplars on Public Land

5

6 Admasu Asfaw Maruta* ${ }^{\dagger}$, Peter Boxall $^{1}$ and Sandeep Mohapatra ${ }^{1}$

8 *Corresponding author:

9 Admasu Asfaw Maruta: Department of Resource Economics and Environmental

10 Sociology, University of Alberta, 515 General Services, Edmonton, AB T6G 2H1,

11 Canada, email: maruta@ualberta.ca

$14{ }^{1}$ Agricultural, Life and Environmental Sciences Resource Economics and

15 Environmental Sociology 515A General Services. Tel. 780-492-5694, e-mail:

16 pboxall@ualberta.ca

17

$18{ }^{1}$ Agricultural, Life and Environmental Sciences Resource Economics and 19 Environmental Sociology 567 General Services. Tel. 780-492-0823, e-mail:

20 sandeep.mohapatra@ualberta.ca

21

22

${ }^{\dagger}$ Current affiliation: Admasu Asfaw Maruta: UniSA Business School | Centre for Applied Finance and Economics University of South Australia | GPO Box 2471 Adelaide | South Australia 5001 t: +61883020315 | f: +61883020092 | email: admasu.maruta@mymail.unisa.edu.au 


\section{Abstract}

24 We investigate the public preference heterogeneity of planting genetically improved

25 poplar tree on public land for biofuel production in Western Canada. Using a sample of 26 the public from British Columbia, Alberta, Saskatchewan, and Manitoba, respondents

27 were asked to vote in a series of hypothetical referenda comparing the new proposed 28 forest policies to the current policy (base scenario). Proposed policies varied based on 29 poplar breeding method (traditional, genomics, or genetic modification) and whether 30 poplars may be used for biofuel production. A respondents' segmentation framework 31 with cluster analysis and probit model was applied to data of respondents to uncover the 32 heterogeneity of public's perception. The results of this study reveal that positive and 33 negative perceptions about planting genetically improved poplar tree in the region 34 create a division of respondents of environmentalists, knowledgeable, challengers and 35 supporters. British Colombians and Manitobans are identified as environmentalists and 36 challengers, respectively, of the new policy of planting genetically improved poplar 37 trees on public land. Conversely, Saskatchewanians and Albertans are identified as 38 supporters and knowledgeable, respectively, of the new policy.

41 Key words: Genomic Technology, Preferences Heterogeneity, Hybrid Poplars, 


\section{Introduction}

The forest industry is important to Canada making significant contributions to

48 regional development, job creation, community stability and foreign exchange.

49 Accordingly, governments have developed and implemented forest policies to enhance

50 public welfare (Tindall et al. 2013). In recent years, however, the Canadian forest

51 industry has experienced decline. This decline has been a result of many structural

52 changes in world markets. For example, the world timber production is now using

53 exotic trees which grow faster and significantly increase profitability (see Payn et al.

54 2015; Carpenter et al. 2004) ${ }^{2}$; but Canada's forest industry is not following this trend.

55 Moreover, the rise of electronic media has decreased the demand for paper by the

56 communication industry. These factors have contributed to the decline in the forest

57 sector; because paper production has been an important driver of the Canadian forest

58 industry. To combat the forestry sector, decline the government is trying to transform

59 the sector by encouraging the development and production of new forest products. One

60 of the new products being considered is the production of cellulosic biofuel from trees.

61 This could involve planting genetically improved poplar trees on public land to produce

62 biofuel (Natural Resources Canada, 2014).

63 Several constraints impede planting genetically improved poplar trees on public

64 land in western Canada. The most important is that most provincial policies about

65 public land management require that forest regeneration needs replanting native trees

66 which are to be produced from the collection of seeds harvested from parent trees

\footnotetext{
2 Payn et al. (2015) show that the Canadian annualized rate of change in planted forest area has decreased from $3.6 \%$ in 2010 to $2.5 \%$ in 2015. Similarly, Haldane and Lyon (2015) suggests that air pollution (mainly acid rain) and global warming significantly decline the amount of timber production, and thereby reduce the contribution of forest sector to the Canadian economy.
} 
67 growing locally. In British Columbia, Alberta, Saskatchewan, and Manitoba harvesting

68 seeds and planting them on public land is rigorously controlled; provincial criteria only

69 authorize the use of native species in which seeds are chosen from neighbouring areas

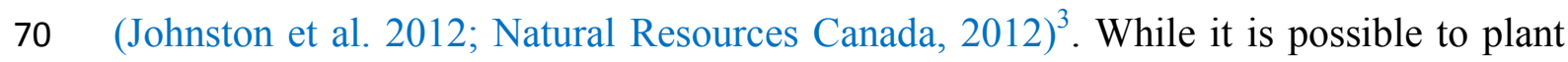

71 non-native trees on private land, many economic and social factors deter the

72 development of plantations of non-native trees on private land. Perhaps the most

73 important factor is that private lands are costlier to acquire and manage than public

74 lands in Canada, making exotic tree plantations on private lands financially infeasible

75 (Anderson et al. 2007).

76 Reforming policies that prohibit planting of exotic trees on public forest lands to

77 give feedstock for biofuels may enhance the profitability of Canada's forest sector.

78 Such reformation would need an understanding of the degree of public support for the

79 public land policy change as well as support for the development of the biofuel

80 industry. However, extant empirical studies which aim at measuring public preferences

81 for the application of biotechnology in forestry give mixed findings. Some of the

82 studies show that citizens are against the use of technology; while others uncover

83 support or neutrality. Kazana et al. (2016) show that the advocates of the applications of

84 biotechnology in forestry argue that this technology has various benefits; such as it

85 increases forest tree productivity through, for example, accelerating tree growth, it

86 restores contaminated soils, and it lowers the demand of pesticides. The authors also

87 reveal that opponents of the application of biotechnology in forestry argue that this

88 technology has various risks to the forest sector; for example, it potentially reduces

\footnotetext{
${ }^{3}$ Rayner et al. (2013) state that Canadian provinces extensively control and regulate forestry activities, derive substantial direct and indirect revenues from these activities.
} 
89 biodiversity though gene flow between transgenic and wild trees, it generates adverse

90 effects on biotrophic processes of host ecosystems, and it foments the costs of

91 controlling pest eruptions and force cultural adaptation to changing biodiversity

92 conditions due to transgene escape.

93 Further, Lucht (2015) argues that environmental NGOs promote protests about

94 genetically modified products, particularly GM foods, by sending "gene detectives"

95 into supermarkets to look for GM labels, and then put strong pressure on shops to

96 immediately remove these legal, authorized and correctly labeled products. Similarly,

97 Kaiser (2001) shows that protests over the use of forest biotechnology have served to

98 motivate individuals to destroy experimental tree plots and even laboratories involved

99 in genetic research relating to forest industries.

Several existing studies argue that inter alia knowledge, gender, presence of

101 various information sources, perceived benefits and risks, and trust in government and

102 scientists are major determinants of preferences towards biotechnology. These factors

103 positively or negatively affect the acceptance of biotechnology and resultant products

104 and commodities. Moreover, lack of genuine information about genetically modified

105 products reduces the acceptance of these products even though they may bring potential

106 environmental and economic benefits. Lucht, 2015; Wieczorek, 2003 shows that

107 environmentalists portray biotechnology as having negative impacts on animal and

108 human health, and on the environment ${ }^{4}$. Similarly, Marques et al. (2015) and Gaskell et

109 al. (2010) find that public acceptance of biotechnology is significantly dependent on

\footnotetext{
4 An environmentalist is an advocate of the goals of the environmental movement. This movement generally embraces political and ethical motives that seek to improve and protect the quality of the natural environment through changes to environmentally harmful human activities (Tesch and Kempton, 2004).
} 
110 their perceptions of risks and benefits, moral and ethical views of genetically modified

111 foods. Therefore, understanding interests and concerns of different segments of the

112 public, and the underlying factors that drive them to support or oppose biotechnology,

113 is important to make good decisions for the application of the technology in forestry ${ }^{5}$.

\section{Prior Literature Review}

115 While many studies examine public preferences towards the application of 116 biotechnology in food and health (e.g. Costa-Font et al. 2009; Pin and Gutteling, 2009),

117 few have been conducted that measure preferences for applications of biotechnology in

118 forestry. This gap likely emanates from the novelty of applying biotechnology in

119 forestry. Moreover, forestry has less direct links with the public compared to food and

120 medicines. $^{6}$ However, Tait (2007) suggests that the public perceives relatively lower

121 levels of risk of applying genetic modification technologies in forestry and food than

122 other ecological risks.

123 Existing empirical studies show many factors affecting the acceptance of

124 biotechnology. For example, Lucht (2015) claims that perception of risks and benefits,

125 knowledge and trust, and personal values significantly influence individuals'

126 acceptance of GM products. Similarly, Kazana et al. 2105; Aleksejeva, 2014 show that

127 the acceptance of biotechnology is higher from individuals who have higher knowledge

128 about biotechnology than those who have lower knowledge of biotechnology. Further,

\footnotetext{
${ }^{5}$ Jessica and Cheng (2011) argue that understanding public value orientations, attitudes and preferences towards national forests is of critical importance for the development and implementation of effective forest policies.

${ }^{6}$ Rollins et al. (2015) argue that individuals are more concerned about the application of genetic modification in food or health due to the presence of private health concerns associated with food or medicine purchase decisions, as the products are to be ingested by humans.
} 
129 based on a large survey of individuals, Zechendorf (1994) documents that knowledge

130 about genetic modification increases the acceptance of biotechnology.

131 The work of Wunderlich and Gatto (2015) show that perceptions of risk, lack of

132 trust in government, scientists, and confidence in controlling organisations may reduce

133 the level of acceptance of biotechnology. Heller, 2003; Sanderson et al. 2003 suggest

134 that general attitudes, and ethical and environmental concerns towards science and 135 technology have significant impacts on accepting genetic modification. They also find

136 that ecocentric individuals argue that genetically modified trees are not environmentally

137 friendly and have long run negative environmental impacts. Barrows et al. (2014)

138 individuals have positive attitudes about the applications of biotechnology in the

139 agricultural sector claiming that agricultural biotechnology reduces uncertainty and

140 breeding time and to transfer traits from more distantly related plants. Gamble et al.

141 (2008) show that there is significant variation among males and females in accepting 142 genetically modified products in which females have less preference for these products.

143 Many studies try to categorise individuals based on their reactions to genetically 144 modified products. Heller (2003) finds three clusters of individuals based on their 145 attitudes towards genetically modified foods from a national survey in the UK. These 146 are: (1) Implacably opposed to biotechnology; (2) Somewhat opposed to biotechnology 147 and (3) No fixed position on genetic engineering. Similarly, Bredahl (1999) finds that 148 consumers' reaction to genetic modification fell into three categories labelled as 149 refusers, undecideds, and triers. Voss et al. (2009) categorised farmers into five clusters 150 based on their preferences for growing genetically improved oil-seed canola in 
151 Germany as supporters, economic skeptics, environmentally and socially influenced,

152 die-hards and strongly opposed.

153 A large survey conducted in the U.S. empirically clustered respondents into 154 three groups based on their attitudes towards biotechnology. These are: (1) Supporters 155 those who feel that biotechnology is useful, not risky, and acceptable; (2) Risk tolerant 156 supporters - those who argue that biotechnology is useful but risky, and morally 157 acceptable; and (3) Opponents - those who claim that biotechnology is risky and 158 unacceptable. Similarly, a result of a large European survey identified four groups of 159 individuals based on perceived risks of biotechnology on human health and 160 environment as: trade-off respondents who saw risks and benefits from genetic 161 modification; relaxed respondents who saw benefits and no risks; skeptical respondents 162 who saw risks and no benefits; and uninterested respondents who saw neither risks nor 163 benefits (Gaskell et al., 2009).

164 There are few studies that systematically measure public preferences for 165 applying biotechnology in forestry (see e.g. Kazana, V et al. 2016; Tsourgiannis et al 166 2016). More specifically, the literature is almost silent about the preference 167 heterogeneity of individuals about the applications of biotechnology in forestry which 168 aim at biofuel production. To this end, our analysis tries to fill the gap in the literature 169 by examining public preferences heterogeneity for planting genetically modified poplar 170 trees on public land for biofuel production in western Canada. Our analysis also gives 171 important understandings of measuring public preferences for the applications of 172 biotechnology in forestry for policy-makers working in provincial and federal 173 governments. 


\section{Questionnaire Design}

Public acceptance information was gathered using a questionnaire administered

177 to internet panels of randomly sampled citizens in the four western provinces of

178 Canada. The development of the questionnaire included many stages of consultation

179 with scientific experts (such as geneticists, botanists and forest scientists), and

180 individuals from the public. Four focus groups were held to assess lay public levels of

181 understanding of forest management and biofuels and to give feedback on early drafts

182 of the hypothetical referendum question formats. These formats outlined attributes and

183 impacts of various policy options compared with the current public land policy

184 involving replanting of trees. Participants for all public focus groups were recruited by

185 telephone using random digit dialing by Advanis Inc. (an Edmonton-based market

186 research firm). Two focus groups each were held in Edmonton, Alberta (16

187 participants), and in Grande Prairie, Alberta (17 participants) to further assess the

188 public's understanding of the forest and biofuel topic. Next, a survey was sent to a

189 group of forestry experts to gather data on predicted changes in poplar growth rate and

190 value arising from different breeding methods. Draft scenarios for hypothetical

191 referendums were developed based on the expert estimates of increases in growth and

192 value of poplars using different breeding methods. A discussion was then held with a

193 group of experts involved with $\mathrm{POPCAN}^{7}$ to ensure that the information provided in the

194 questionnaire was accurate. Following further reviews, a final round of public focus

\footnotetext{
${ }^{7}$ POPCAN is a project which aims to harness genomic information to enhance the appropriateness of poplars as a cellulosic biofuel feedstock (Genome British Columbia, 2014).
} 
195 groups was held, with two groups in Edmonton, Alberta (24 participants), and two 196 groups in North Battleford, Saskatchewan (22 participants). This round of focus groups

197 aimed to ensure that all elements of the questionnaire were understood by respondents 198 and to reduce potential sources of bias.

199 After completing these stages, a pretest version was administered online to 102 200 respondents (51 Albertans, and 51 British Columbians) of an internet panel maintained 201 by Ipsos Canada, a market research firm. The final questionnaire gave a brief 202 explanation about biofuels, various tree breeding methods, and information about the 203 prevailing forest composition, industry, and policy in each of the four provinces. This 204 was followed by a series of hypothetical referendum questions which were framed as a 205 binary choice in terms of a vote for the current policy about public land reforestation 206 and current tree breeding methods or a vote for a new policy option which allowed the 207 planting of exotic trees on public land using more sophisticated breeding technologies. 208 The referenda were followed with some follow-up questions and the collection of 209 demographic information.

210 The hypothetical referenda involved six proposed policy alternatives, each of 211 which was driven by two main attributes which were the tree breeding method 212 employed, and whether poplars would be used for biofuel production. The breeding 213 method was based on three tree breeding methods: traditional selective breeding, 214 genomics-assisted breeding, and genetic modification. The three breeding methods 215 appeared with and without a biofuel production attribute i.e. traditional breeding with 216 and without biofuel, genomics-assisted breeding with and without biofuel and genetic 217 modification with and without biofuel production. Each respondent was given a chance 
218 to vote between the current policy (i.e. traditional breeding without biofuel production)

219 and the new proposed policy.

220 An example referendum question is shown in Figure 1. In each policy

221 alternative, participants were given information about the location of parent trees,

222 breeding methods, how commercial public land in their province is used, impact on the

223 forest industry and the estimated amount of carbon emission reduction from using

224 poplar derived biofuels in their province. The respondents were also given colored

225 graphical and hyperlink information that provided definitions of each tree breeding

226 method. In the base scenario, parent trees would come from the same region as

227 replanted trees; trees would be bred suing traditional breeding methods and there would

228 be no impact on jobs, income and carbon emission reduction. The new proposed

229 policies' parent trees could come from anywhere; they may have impacts on jobs,

230 income and carbon emission reductions in the province. Furthermore, assessments of

231 commercial public forest land-use were given that consisted of four elements: land with

232 non-harvested forest and land with harvested coniferous trees, natural poplars, and

233 improved poplars. There was a fixed (40\%) harvested level of coniferous treed land in

234 the referendum for both current and the new proposed policies.

235 Current commercial forest land-use was calculated for each province using a 236 variety of sources, depending on data availability. British Columbia forest land-use was

237 calculated using a collection of 40 timber supply area analysis reports prepared by the

238 BC Ministry of Forest, Lands, and Natural Resource Operations (2014). Alberta forest

239 land-use was calculated using data from Alberta Environment and Sustainable Resource

240 Development (2013). For Saskatchewan and Manitoba, data was not easily available 
241 from the provincial governments, so land-use was estimated based on information

242 released by forestry firms. For example, reports from Mistik Management Ltd. (2013)

243 and Tolko Industries Ltd. (2014) were used to calculate the current commercial forest

244 land-use in Saskatchewan and Manitoba respectively. Simulation results from Anderson

245 et al. (2012) were used to decide the expected changes in land-use due to allowing

246 different breeding methods and seed selection on public land. In all proposed policy

247 alternatives, equal annual-allowable-cut (AAC) was taken into consideration where the

248 same volume of timber would be harvested under each policy alternative. Technically,

249 higher tree growth rates might show a higher annual-allowable-cut (AAC) instead of 250 leaving some areas unharvested, but a constant AAC was assumed to avoid 251 confounding the area to be planted with genetically improved poplars using different 252 tree breeding methods.

255 composition and current land-use in each province was combined with the results from 256 Anderson et al. (2012) to estimate the impact of allowing new tree breeding methods on 257 the forest industry, specifically on the levels of income and job opportunities. Based on $2585 \%$ of Alberta's gasoline being replaced by poplar-derived biofuel, estimates of life259 cycle analysis carbon emission reduction of second-generation biofuels from Schmer et 260 al. (2008), and gasoline consumption data from Statistics Canada (2013) were used to 261 estimate potential reductions in carbon emissions per year by planting genetically 262 improved poplar trees on public land. 


\section{Questionnaire Administration}

264

265

266

267

268

269

270

271

272

273

274

275 Ipsos Canada and they were not informed of the study topic when invited to

276 participate ${ }^{10}$. Internet based surveys may face sampling bias issues in the sense that

277 internet access is a requirement. However, internet accessibility is increasing through

278 time in all provinces of Canada. According to Statistics Canada (2013), 83\% of

279 Canadians, who were above the age of 18, had internet access at their home, which was 280 greater than the level in $2010(79 \%)$.

\section{Cluster Analysis}

\footnotetext{
${ }^{8}$ The data were collected in 2015.

10 The respondents could win valuable cash prizes or goods, while making their opinion known.
} 
284 respondents into small sub-clusters. Then, the procedure categorises the sub-clusters

285 into the optimal number of clusters based on similarities of the underlying variables,

286 which were, attitudinal variables in this study. This two-step clustering procedure has

287 various advantages over other traditional clustering algorithms such as K-means, K-

288 median and Hierarchical techniques where all of them involve researcher selected

289 determination of the number of clusters. Some of the advantages of the two-step

290 clustering are: (1) it can create clusters based on both categorical and continuous

291 variables; (2) it selects the number of clusters automatically without any human

292 intervention that might create bias in the number of clusters; and (3) it is able to handle

293 and analyse large datasets efficiently. We used SPSS version 24.0 to generate distinct

294 clusters of respondents. ${ }^{11}$

295 For clustering variables, we used a series of measures from respondents. These

296 included: attitudes towards science and research; New Ecological Paradigm (NEP)

297 scores; ${ }^{12}$ measures of trust in federal and provincial governments, in scientists, the

298 forest industry, and in environmental non-government organizations (ENGOs); and

299 measures of knowledge of forest operations and biotechnology. Each clustering

300 variable had a variable number of items. For example, respondents' attitude towards

301 science and research were measured using a 7-item Likert scale developed by Bauer et

302 al. (2000). (see Appendix $1^{13}$ ). Environmental values were measured by the 15 -item

\footnotetext{
${ }^{11}$ SPSS software is highly efficient to conduct two-step clustering procedures (Bacher et al. 2004).

${ }^{12}$ Stern et al. (1995) conclude that the NEP scale measures generalised beliefs about the nature of humanenvironment interactions which include individuals' valuations and attitudes about specific environmental conditions.

${ }^{13}$ Appendix 1 shows indicators of NEP and attitudes towards science and research. Other clustering factors' items are available from the senior author upon request.
} 
303 New Ecological Paradigm scale (Dunlap et al. 2000). Trust in the federal government, 304 provincial government, industry, scientists, and environmental non-government 305 organizations were each measured using a four-item scale developed by Lang \& 306 Hallman (2005). Knowledge of forests and forest management was measured by six 307 indicators compiled by McFarlane \& Boxall (2000). Biotechnology knowledge was 308 measured using a scale of 10 items from the Eurobarometer 58.0 questionnaire (Gaskell 309 et al. 2003).

We applied statistical techniques such as factor analysis (FA), sum of scale

311 items and principal component analysis (PCA) to minimize the number (dimension) of 312 items which had strong correlations among them to reduce redundancy (duplication) of 313 items. However, PCA and FA have some limitations, as they can compress many scale 314 items to fewer items which in turn may cause loss of important information from the 315 original items as suggested by Karamizadeh et al. (2013). On the other hand, Comrey et 316 al. (1992) state that employing the sum of each item (summed scale) does not lose 317 potential information from the original items. Moreover, Hair et al. (2006) argue that

318 the summed scale is the simplest and desirable method of reducing items by preserving 319 the variation in the original data. It is also a well-accepted approach for most 320 exploratory analysis (Tabachnick et al., 2001). Hence, we used the sum of items of each 321 clustering factor in our analysis. The scales of clustering factors are normalised using 322 standardized scores as it is the default standardisation technique in SPSS two-step 323 clustering analysis (see Bacher et al. 2004).

\section{Other Statistical Methods Employed}



the referenda information associated with the respondents in each cluster to examine the

327 likelihood of choosing a specific policy option relative to the current policy. Random

328 utility theory proposes that individuals choose policy alternatives that yield the greatest

329 utility compared to other policy alternatives. Therefore, the probability of choosing an

330 alternative policy increases as the utility associated with them increases (Burton et al.

331 2001). Based on this argument, we applied a binary probit choice model for each cluster

332 (see equation 1). With a binary outcome variable, where the observed choice $C_{n k m}=1$

333 shows a vote by respondent $n$ in cluster $k$ in favour of a newly proposed policy

334 alternative $m$, and $C_{n k m}=0$ denotes a vote for the current policy. Equation 1 posits 335 that $U_{n k m}$ then implies the latent utility of respondent $n$ in cluster $k$ related to voting for 336 the newly proposed forest policy $m$ over the current policy:

$$
U_{n k m}=a_{k}+\theta_{k}^{\prime} P_{m}+v_{n m}
$$

338 Where; $C_{n k m}=1$ if $U_{n k m}>0$ and $C_{n k m}=0$ otherwise. $P_{m}$ is a vector of policy 339 attributes associated with alternatives, $a_{k}$ and $\theta_{k}^{\prime}$ are estimated coefficients, and $v_{n m}$ is 340 mean-zero, and normally distributed error term. The parameters in equation (1) were 341 estimated using a binary probit model for each cluster. Since there are multiple clusters 342 of respondents and six votes per respondent, it is possible that the errors in each cluster 343 can be correlated. To solve this issue, a robust cluster-corrected Huber-White sandwich 344 estimator was applied which allows $v_{n m}$ to be correlated within clusters, but not across 345 clusters (Huber 1967; White 1980).

\section{Findings and Discussion}


Table 1 presents the comparison of sample and population demographics. Males 348 were slightly under-sampled as compared to females in all provinces. In Alberta and

349 British Columbia, cities with the population greater than 100,000 were under-sampled.

350 However, cities with the population 10,000-100,000 and less than 10,000 were over-

351 sampled. In Manitoba and Saskatchewan, samples and populations are very close in

352 terms of population sizes of residences. In all provinces, samples have higher post-

353 secondary education rates than their respective populations. However, it is more likely

354 that the population education rates are slightly larger than listed as the population data

355 refers to all Canadian residents over 15 years of age, while our sample is based on

356 individuals over 18 years of age. Thus, it is not surprising that the sample has higher

357 post-secondary education rates than the population. Most respondents took between 15

358 and 30 minutes to complete the survey.

The overall quality of our clustering procedure falls in the good range. ${ }^{14}$ Further,

361 two-step clustering uses a silhouette algorithm to measure cluster cohesion and 362 separation and shows how closely related the objects within each cluster, and how 363 distinct a cluster is from other clusters. It also shows the average dissimilarity of an 364 observation $i$ with all other observations within the same cluster; where a smaller 365 average value shows the better assignment of the observation to a given cluster. Let $366 a(i)$ be the average dissimilarity of observation $i$ in one cluster and $c(i)$ be the lowest 367 average dissimilarity of observation $i$ to any other cluster, of which $i$ is not a member.

\footnotetext{
${ }^{14}$ The two-step clustering technique provides three ranges (poor, fair and good) to measure the overall quality of the clustering process.
} 
368 The cluster with this lowest average dissimilarity is said to be the neighbouring cluster

369 of $i$ because it is the next best fit cluster for this observation. Hence, the silhouette of

370 observation $i, s(i)$, can be defined as:

$$
s(i)=\frac{c(i)-a(i)}{\max \{a(i), c(i)\}} .
$$

372 This

can

also

be

written

as:

$$
s(i)= \begin{cases}1-a(i) / b(i), & \text { if } a(i)<c(i) \\ 0, & \text { if } a(i)=c(i) \\ c(i) / a(i)-1, & \text { if } a(i)>c(i)\end{cases}
$$

From equations (2) and (3), it is possible to conclude that $-1 \leq s(i) \leq 1$. When

$375 s(i)$ is close to 1 , observation $i$ is well matched to a given cluster; which in turn shows

376 that the clustering procedure was proper; and vice versa when $s(i)$ approaches -1

377 (Kaufman et al. 2009). Hence, the quality of clustering process in this study falls in the

378 good range (approaches to 1), as depicted in Figure 2. This shows that respondents 379 within each cluster have closely similar patterns of characteristics, and those across 380 clusters have different characteristics.

We labelled each cluster based on characteristics of respondents in each cluster; this consisted of the mean values of the clustering factors (see Table 3) and the relative 384 percentage of members voting for new policies (see Table 4). Members of cluster 1 are 385 labelled as Environmentalists since they have the highest mean value for the New 386 Ecological Paradigm scale which assesses a measure of environmentalism attitudes. 387 Respondents in cluster 2 are labelled as Knowledgeable as they have the highest mean 
388 values of knowledge of biotechnology. Those respondents in cluster 3 are labeled as 389 Challengers as they have the highest voting percentages of traditional breeding 390 compared to DNA breeding and genetic modification both with and without biofuel 391 production. Finally, members of cluster 4 are labelled as Supporters of the new policy 392 alternatives because they have the lowest voting percentage for the current policy393 traditional breeding methods.

In Table 2, we show the total number and percentage of respondents in each 395 cluster. For example, the Environmentalists cluster holds the highest and lowest 396 percentages of British Columbians and Saskatchewanians respectively. Figure 3 shows 397 the importance of clustering factors in each cluster. Environmentalists show high 398 tendencies of trust in environmental non-governmental organisations (ENGOs).

400 This factor takes the highest share in the formation of Environmentalists' cluster. The 401 NEP score is the second most important element in the formation of Environmentalists 402 cluster. Other clustering factors including trust in scientists, forest industry and federal 403 and provincial governments have lower importance in the formation of 404 Environmentalists cluster. NEP score is the most important factor in the formation of Challengers' cluster. 406 This shows that Challengers have similar environmental perceptions with 407 Knowledgeable respondents. However, attitudes towards science and research and trust 
409 in forest industry and scientists are the least important factors in the formation of 410 Challengers' cluster. Finally, trust in the forest industry, federal and provincial

411 governments are the most important factors in the construction of Supporters' cluster. It

412 is important to note that in Figure 3 the NEP score, knowledge of forest operations and

413 biotechnology seem to be the highest mean value in the formation of all clusters.

414 The main reason is that the NEP has 15 questions which are scaled in a five415 point Likert scale from strongly disagree (with the value 1) to strongly agree (with the 416 value 5). Thus, the minimum and maximum sums of the scale items are 15 and 75

417 respectively. Similarly, the percentages of correctly answered facts were considered for 418 knowledge of forest operations and biotechnology in which the minimum and 419 maximum percentages are $16 \%$ and 100\% (for knowledge of forest operations) and $42010 \%$ and $100 \%$ (for knowledge of biotechnology), respectively. However, there are 421 significant differences in the values of these clustering factors across clusters. In Table 3 we present the exact values of each clustering factor in all clusters.

424 Table 4 shows the demographic variables in each cluster. In all clusters, the number of 425 females is higher than the number of males. The Challengers cluster has the highest 426 percentage of respondents whose age is between 35 and 64. 
In Table 5 we show the percentage of vote in favour of the new forest policy

429 alternatives. Environmentalists vote for current policy $(60.43 \%)^{15}$ compared with

430 genetic modification (39.57\%). They also have lower preference for DNA breeding

$431(40.22 \%)$ than traditional breeding (59.78\%). However, they prefer new policies if it is

432 accompanied by biofuel production (53.39\%) compared to the current policy (46.61\%).

433 Challengers are in favour of the current policy which involves traditional poplar

434 breeding. Further, Supporters are in favor of the new policy alternatives with and

435 without biofuel production. They have similar preference patterns with Knowledgeable

436 and have identical preferences for DNA breeding methods (nearly 50\%).

Insert Table 5

Environmentalists are in favour of the newly proposed policy alternative if

439 biofuel production goes with it. The level of trust in scientists, federal and provincial

440 governments have less importance in the make-up of this cluster (see Figure 3). These

441 factors could induce skepticism among respondents towards biotechnology. However,

442 several empirical studies show mixed findings about the effect of trust on public

443 acceptance of biotechnology. For example, Finlay et al. (1999) suggest that trust has

444 insignificant effect on public acceptance of biotechnology. On the other hand, Priest

445 (2003) and James (2005) show that trust has significant and positive effect on public

446 acceptance of biotechnology.

448 emanated from the fact that most of environmental organisations are continuously

\footnotetext{
${ }^{15}$ The vote percentages of traditional breeding compared to DNA breeding, genetic modification and biofuel in cluster 1 are 59.78, 60.43 and 46.61; in cluster 2 are 49.62, 52.5 and 38.86; in cluster 3 are $59.91,62.71$ and 57.48; and in cluster 4 are $49.89,48.47$ and 40.55 respectively.
} 
449 promoting the negative consequences of biotechnology. For example, Wieczorek 450 (2003) shows that environmentalists usually argue that inadequate effort has been made

451 to understand the risks of using transgenic crops. They further demand rejection of 452 genetic modification R\&D activities. This potentially implies that if individuals higher 453 trust in these organisations, they may rely on the information provided by these 454 institutions and tend to have "reluctant" attitudes for biotechnology. Moreover, 455 Environmentalists have higher mean values of knowledge of biotechnology and forest 456 operations suggesting that accepting biotechnology and knowledge have an inverse 457 relationship. This is compatible with the finding of Sholdere (2003) which shows that 458 high level of knowledge encourages individuals to ask more critical questions about the 459 technology which in turn induces scepticism among individuals. In contrast, Hoban 460 (1997) finds that individuals with higher level of knowledge tend to accept the 461 application of biotechnology. Klerck and Sweeney (2007) show that knowledge about 462 genetically modified food significantly reduces psychological risks. They further 463 suggest that cooperation among government, scientific institutions, and the food 464 industry to foster effective communication strategies that increase consumers' 465 knowledge, reduce their risk perceptions, and encourage consumer adoptions of 466 biotechnology. British Columbians and Saskatchewanians form the highest and lowest, 467 respectively, percentages of Environmentalists. Most of the respondents in this cluster 468 are engaged in non-farming activities and live in urban areas.

Knowledgeable respondents have higher mean values of the NEP score, 470 knowledge of forest operations and biotechnology. The main reason for having some 471 hesitations about biotechnology may associate with these factors as showed by large 
472 empirical studies. For example, Kaiser (2001) argues that tree engineering is coming

473 under fire from environmental groups as it has moved from the laboratory into the

474 field-testing stage. Mann et al. (2002) show that planting transgenic trees has arrived at

475 a critical juncture now that environmental concerns are becoming the main obstacles to 476 get public acceptance of these trees. Further, Campbell et al. (2001) uncover that

477 opponents are calling for suspension of commercial release of genetically modified 478 food and plants until the long-term environmental impacts are better assessed and 479 understood. Manitobans hold the lowest percentage of the Knowledgeable respondents.

All clustering factors, except the NEP score, have lower mean values in cluster 3-Challengers. The higher mean value of NEP score may significantly show that the environmentalism attitude reduces the level of accepting genetically modified products.

483 Blay (2005) finds that environmentalists argue that genetically modified plants 484 negatively affect the nature through massive and long-run intoxication of the 485 environment. Ganiere et al. (2006) find that rejecting genetic modification have strong 486 correlation with the loss of trust in different stakeholders, lack of information, 487 perceived risks and lack of knowledge about the biotechnology. Moreover, Nelson 488 (2001) and Onyango et al. (2006) show that opponents of biotechnology argue that 489 genetically modified products contaminate organic seeds and foods through various 490 mechanisms including pollination. Manitobans form the highest percentage of 491 respondents in the Challengers' cluster.

492 Finally, respondents in the Supporters' cluster have lower mean value of NEP 493 score; and this may infer that members of this cluster have optimistic attitudes about 
494 biotechnology as reported by IPCC $(2001)^{16}$. IPCC shows that supporters of

495 biotechnology in forestry argue that the technology restores species which are severely

496 damaged by pests and disease. It also mitigates the build-up of atmospheric greenhouse

497 gases (including carbon) that believed to be the main causes of global warming.

498 Respondents in Supporters' cluster have higher mean values of trust in federal and

499 provincial governments. This may in turn show that supporters of biotechnology in

500 forestry have more confidence about formulating and enforcing different types of rules

501 and regulations related to the technology as documented by Hossain et al. (2003); and

502 Onyango, et al. (2006). Moreover, trust in scientists plays an important role in the

503 make-up of the Supporters' cluster. Similar with this finding, Siegrist et al. (2012)

504 suggests trust in scientists significantly increases the acceptance of biotechnology.

505 Around $37 \%$ of members of Supporters' cluster are from Saskatchewan.

506 According to Pew Research Centre (2010) Saskatchewan is recognised as hosting one

507 of the world's leading ag-biotech research centres. It also shows that $30 \%$ of Canadian

508 ag-biotech industries are in Saskatchewan. These research centers created the world's

509 first genetically modified commercial canola variety and the first genetically engineered

510 animal vaccine. In addition, the research center pays significant attention to creating

511 public awareness about biotechnology and genetically modified products. This may

512 show that Saskatchewanians have advantages, compared with residents of other

513 provinces, of accessing updated information and acquiring different types of

514 information regarding biotechnology and resultant products. Hence, this might be

515 considered as one of the main factors that induces the level of accepting the application

516 of biotechnology in forestry (Hamstra, 1998).

\footnotetext{
${ }^{16}$ Intergovernmental Panel on Climate Change
} 
517 We used a binary probit model to examine the likelihood of voting the newly proposed 518 policy alternative relative to the current policy. The vote for policy alternative takes the

519 value 1 if a respondent, who is assigned in a specific cluster, chooses the newly 520 proposed policy alternative; and 0 otherwise. The covariates are the three types of 521 breeding methods TB, DNA and GM in which all of them are accompanied with and 522 without biofuel production. Table 6 provides parameter estimates of the models, and 523 Table 7 shows the associated marginal effects of changes in the variables relative to a 524 base scenario in each cluster.

526 The marginal effect of DNA breeding shows that the probability of voting for 527 DNA breeding by Environmentalists declines by $3.2 \%$ relative to the base scenario. 528 Employing GM technologies seems less impactful, as the marginal effect associated 529 with this policy alternative is $-1.6 \%$. However, if any new policy employing 530 biotechnology is used to produce biofuels, the probability of voting for this new policy 531 increases by $32.4 \%$.

532 Table 7: A summary of marginal effects from probit model estimates in each cluster in 533 terms of a percent change in the probability of voting to support a new policy with a 534 one unit change in the variable.

536 Knowledgeable respondents are more likely to vote for a new policy when the 537 new poplar breeding method employs DNA breeding as the likelihood of voting for it 538 increases by $1.7 \%$. Applying GM has lower impacts on voting as the marginal effect 
539 related to the policy choice declines by $6.1 \%$. Conversely, if the new forest 540 management strategies applying biotechnology is used to produce biofuels, the

541 likelihood of voting for the new forest policy increases by $38.4 \%$. The negative opinion

542 towards GM might be caused by the higher value of NEP score. Peelle (2000) suggests

543 that individuals with environmental attitudes seek more information about the

544 environmental impacts and net benefit of applying biotechnology. This evidence

545 indicates that if Knowledgeable respondents get more information about biotechnology,

546 the probability of voting for applying the technology would increase in a significant

547 rate.

548 The probability of voting for DNA breeding is less likely in the Challengers' 549 cluster as the marginal effect associated with this breeding method is declined by $5503.6 \%$. Applying GM appears to be less effective, as the marginal effect of this 551 technology is declined by 5.1\%. Moreover, if the new policy employing biotechnology 552 to forest policy is used to produce biofuels, the probability of voting for the new policy 553 will decline by $27.5 \%$. The lowest mean values of the indicators of trust in scientists, 554 forest industries, provincial and federal government can be considered as one of the 555 main drivers of Challengers for not voting the newly proposed polices. This result is 556 similar with the finding of Snow et al. (2005) which reveals that opponents of 557 genetically modified trees argue that the uncertainties and ecological impacts of these 558 trees need higher engagement of different civil societies and governments. Thus, the 559 federal and provincial governments should formulate and implement various regulatory 560 frameworks to reduce the negative impacts of genetically improved trees and increase 561 the public acceptance of biotechnology (see e.g., Curtis et al. 2004). 
The marginal effect of DNA breeding in Supporters' cluster shows that if the

563 newly proposed policy employs this breeding method, the probability of respondents to

564 vote for the new policy will be enhanced by $0.4 \%$. Similarly, applying GM seems more

565 impactful in which the probability of voting for the new forest policy increases by $2.7 \%$

566 compared to the base scenario. Finally, if the new policy is accompanied by biofuel,

567 supporters would vote this policy in which the probability is increased by $29.3 \%$ 568 percent.

\section{Conclusion and Policy recommendations}

570 This study examines aspects of public preferences for introducing new genomic

571 technologies to produce hybrid poplars to be used as biofuel feedstock from public

572 forest lands in western Canada. Six new policy scenarios for each province were

573 provided to respondents that considered the use of three different breeding methods

574 (Traditional, DNA breeding, Genetic Modification), each with and without poplars

575 being used for biofuels. We use a referendum format to present alternative policy

576 scenarios to examine the differences between characteristics of the group of

577 respondents. All proposed policies allowed unrestricted seed choice for reforestation of

578 poplars in each province on public land. Respondents were asked to vote in a series of

579 hypothetical binary referenda among with each new policy and the current policy,

580 based on changes to forest land use, breeding methods, impacts on industry, and 581 impacts on carbon emissions.

582 We found four clusters of respondents in our samples (Environmentalists,

583 Knowledgeable, Challengers and Supporters) based on their preferences towards the 584 application of breeding technologies in forestry for biofuel production using the two- 
585 step clustering procedure. Overall, we found large support across all clusters but one 586 (Challengers) for policies that allowed genetically improved poplars to be planted on 587 public land if the polices were accompanied by biofuel production. For example, the 588 likelihood of accepting the newly proposed policies increases from $2.7 \%$ to $29.3 \%$ if 589 biofuel production goes with these policies, particularly in the Supporters cluster. There 590 is no significant variation in the acceptance of different breeding technologies if biofuel 591 production is not a part of the policy (see Table 7). Thus, the use of poplar as a biofuel 592 source increases the likelihood of the western Canadian public choosing scenarios that 593 allow the application of new breeding technologies such as genetic modification on 594 public land. These variations in relation to the presence or absence of biofuel 595 production within newly proposed allowances for planting exotic poplars on public 596 forest land may potentially help policy-makers to reform Canadian forest polices.

597 Our findings show that individuals have different preferences for changes in 598 forest operations in western Canada. We also try to show some of the conditions which 599 have significant effects on individuals' preferences for the application of biotechnology 600 in forestry. Individuals' environmentalism attributes and attitudes towards science and 601 research appear important determinants of accepting the application of biotechnology in 602 Canadian forest sector. Knowledge of biotechnology also plays an import role 603 increasing the probability of accepting genetically modified poplar trees. Thus, policy 604 makers should guarantee the dissemination of biotechnology scientific knowledge to 605 assure a high level of knowledge among individuals. Trust in government has salient 606 contribution in giving information to individuals to allow them to undertake informed 607 and ideally reasoned choices. 

information on new technology developments that eventually determines acceptance.

610 Therefore, policies that aim at maximizing the acceptance of new developments in the 611 forest sector should operate in various aspects including the media, the education 612 system, and a correct population analysis to determine information availability and 613 processing through individuals transmission of values and societal trust enhancing 614 factors. These policies need to create awareness about the benefits of the newly 615 developed technologies which potentially avoid ambiguities concerning the potential 616 perceptions of risk associated to the technologies.

617 Although forest products from genetically modified trees might not be in the 618 market soon, marketing claims concerning the non-GM nature of forest products should 619 be administered, as it may upsurge individuals' perception of risk. Further, 620 scientifically based information on the expected purchasing behaviour of individuals 621 has important contribution for developers and policy makers. For the developers this 622 type of information is imperative, as the anticipation of feasible markets will stimulate 623 investments. For the policy makers, such information will support them to develop 624 proper decision-making positions and respond more effectively through rules and 625 regulations. However, further investigations need to be conducted to gain better 627 understanding of why individuals' preferences are heterogeneous in voting for the 628 application of biotechnologies in forestry. For example, examining the heterogeneity of 629 preferences for the application of biotechnology to forestry in other provinces using 630 different measures of preferences would give important contributions to understand 
631 why individuals' preferences for the application of biotechnology in forestry are

632 different. Empirically, this is an interesting and open area for further research. 


\section{Acknowledgements}

Funding for this research was provided by Genome Canada, Genome British Columbia, Genome Alberta, and Alberta Innovates Bio Solutions. Student financial support from the Al Brennan Memorial Scholarship is gratefully acknowledged. 


\section{References}

Aldrich, G.A., Grimsrud, K.M., Thacher, J.A., and Kotchen, M.J., 2007. Relating environmental attitudes and contingent values: how robust are methods for identifying preference heterogeneity? Environmental and Resource Economics, 37: 757.

Aleksejeva, I., 2014. Latvian consumers' knowledge about genetically modified organisms. Organizaciju vadyba: sisteminiai tyrimai, 72: 7-16.

Anderberg, M.R., 2014. Cluster analysis for applications: probability and mathematical statistics: A series of monographs and textbooks. Academic press.

Anderson, J.A., Armstrong, G.W., Luckert, M.K., and Adamowicz, W.L. 2012. Optimal zoning of forested land considering the contribution of exotic plantations. Mathematical and Computational Forestry \& Natural-Resource Sciences, 4: 92-104.

Anderson, J.A., and Luckert, M.K., 2007. Can hybrid poplar save industrial forestry in Canada? A financial analysis in Alberta and policy considerations. The Forestry Chronicle, 83: 92-104.

Anderson, J.C., Wachenheim, C.J. and Lesch, W.C., 2005. Perceptions of genetically modified and organic foods and processes: North Dakota college students. Department of Agribusiness and Applied Economics, Agricultural Experiment Station, North Dakota State University.

Bacher, J., Wenzig, K., and Vogler, M., 2004. SPSS Two-step Cluster-a first evaluation.

Barrows, G., Sexton, S. and Zilberman, D., 2014. Agricultural biotechnology: the promise and prospects of genetically modified crops. Journal of Economic Perspectives, 28: 99-120.

Bauer, M. W., Petkova, K., and Boyadjieva, P., 2000. Public knowledge of and attitudes to science: Alternative measures that may end the "science war". Science, Technology \& Human Values, 25: 3051.

Blay, S., 2005. International regulation of biotechnology: Problems and prospects. Journal of International Biotechnology Law, 2: 245-251.

Bredahl, L., 1999. Consumers' cognitions with regard to genetically modified foods: Results of a qualitative study in four countries. Appetite, 33: 343-360.

British Columbia Ministry of Forest, Lands, and Natural Resource Operations (2014). Timber supply review: TSR and TSA schedule. http://www.for.gov.bc.ca/hts/aactsa.htm.

Burton, M., Rigby, D., Young, T., and James, S., 2001. Consumer attitudes to genetically modified organisms in food in the UK. European Review of Agricultural Economics, 28: 479-498.

Campbell, F.T., and Asante-Owusu, R., 2001. GE trees: proceed only with caution. In Proceedings of the First International Symposium on Ecological and Societal Aspects of Transgenic Plantations, 158-167

Carpenter, F. L., Nichols, J. D., and Sandi, E., 2004. Early growth of native and exotic trees planted on degraded tropical pasture. Forest Ecology and Management, 196: 367-378.

Comrey, A.L., and Lee, H.B., 1992. A First Course in Factor Analysis (2nd edn.) Lawrence Earlbaum Associates. Publishers: Hillsdale, New Jersey.

Costa-Font, M., Gil, J.M., and Traill, W.B., 2008. Consumer acceptance, valuation of and attitudes towards genetically modified food: review and implications for food policy. Food Policy, 33: 99-111. 
Curtis, K.R., McCluskey, J.J., and Wahl, T.I., 2004. Consumer acceptance of genetically modified food products in the developing world.

Dunlap, R. E., Van Liere, K. D., Mertig, A. G., \& Jones, R. E., 2000. New trends in measuring environmental attitudes: measuring endorsement of the new ecological paradigm: a revised NEP scale. Journal of Social Issues, 56: 425-442.

Duran, B.S. and Odell, P.L., 1974. Cluster analysis, a survey, volume 100 of lectures notes in economics and mathematical systems.

Finlay, K., Susan, M., Jane, L., and Trevor, W., 1999. The Impact of Information and Trust on Consumer Perceptions of Biotechnology. Canadian Journal of Marketing Research, 18: 15-30.

Gamble, J., and Elsa, K., 2008. The use of selected community groups to elicit and understand the values underlying attitudes towards biotechnology. Public Understand of Science, 17: 245-259.

Ganiere, P., Chern, W.S., and Hahn, D., 2006. A continuum of consumer attitudes toward genetically modified foods in the United States. Journal of Agricultural and Resource Economics, 129-149.

Gaskell, G., Stares, S., Allansdottir, A., Allum, A., Castro, P., and Esmer, Y., 2010. Europeans and biotechnology in 2010: Winds of Change? The $7^{\text {th }}$ series of Eurobarometer surveys on life sciences and biotechnology.

Gaskell, G., Allum, N. C., Bauer, M. W., Jackson, J., Howard, S., and Lindsey, N., 2009. Ambivalent GM nation? Public attitudes to biotechnology in the UK, 1991-2002. Life Sciences in European Society Report: London School of Economics and Political Science.

Gaskell, G., Allum, N., and Stares, S., 2003) Europeans and biotechnology in 2002: Eurobarometer 58.0. Brussels: European Commission. Hair, J.F., Black, B., Babin, B., Anderson, R.E., and Tatham, R.L., 2006. Multivariate data analysis, 6. Baskı. Upper Saddle River, NJ: Pearson Prentice Hall).

Haldane, J.B.S. and Lyon, K.S., 2015. The long-term adequacy of world timber supply. Routledge.

Hambrick, D. C., S. Finkelstein, T.S. Chove, E.M. Jackson (2005). Isomorphism in Reverse: Institutional Theory as an Explanation for Recent Increases in Intraindustry Heterogeneity and Managerial Discretion. Research in Organizational Behavior, 26: 307-350.

Hamstra, A., 1998. Public opinion about biotechnology: A survey of surveys. European Federation of Biotechnology, Task Group on Public Perceptions of Biotechnology.

Heller, R., 2003. GM Nation? The findings of the public debate. UK Department of Trade and Industry.

Hoban, T.J., 1997. Consumer acceptance of biotechnology: an international perspective. Nature biotechnology, 15: 232.

Hossain, F., Onyango, B., Adelaja, A., Schilling, B., and Hallman, W., 2002. Uncovering Factors Influencing Public Perceptions of Food Biotechnology. Food Policy Institute. Working Paper 0602003 .

Huber, P.J., 1967. The behavior of maximum likelihood estimates under nonstandard conditions. In Proceedings of the 5th Berkeley Symposium on Mathematical Statistics and Probability, Berkeley, California, 21 June-18 July 1965 and 27 December 1965, 1967 January 1966. Edited by Lucien M. Le Cam and Jerzy Neyman. Statistical Laboratory of the University of California, Berkeley, California, 221-233.

Intergovernmental Panel on Climate Change (IPCC), Annual report (2014). 
James, H.S., 2005. Trust in scientists and food manufacturers, with implications for the public support of biotechnology.

Jessica, C. M., and Cheng, A.S., 2011. Using analyses of public value orientations, attitudes and preferences to inform national forest planning in Colorado and Wyoming. Applied geography, 31: $393-400$.

Johnston, M.H., Williamson, T.B., Price, D.T., Spittlehouse, D.L., Wellstead, A.M., Gray, P.A., Scott, D., Askew, S.E. and Webber, S.L., 2006. Adapting forest management to the impacts of climate change in Canada.

Kaiser, J., 2001. Words (and axes) fly over transgenic trees. Science, 292: 34-36.

Kamakura, A. W., Kim, D. B., and Lee, J. (1996). Modeling preference and structural heterogeneity in consumer choice. Marketing Science, 15: 152-172.

Karamizadeh, S., Abdullah, S.M., Manaf, A.A., Zamani, M. and Hooman, A., 2013. An overview of principal component analysis. Journal of Signal and Information Processing, 4: 173.

Kaufman, L., and Rousseeuw, P.J., 2009. Finding groups in data: an introduction to cluster analysis (Vol. 344). John Wiley \& Sons.

Lang, J. T., and Hallman, W. K., 2005. Who does the public trust? The case of genetically modified food in the United States. Risk Analysis, 25: 1241-1252.

Lucht, J.M., 2015. Public acceptance of plant biotechnology and GM crops. Viruses, 7: 4254-4281.

Mann, C. C., and Plummer, M. L., 2002. Forest biotech edges out of the lab. Science, 295: 1626-1629.

Marques, M.D., Critchley, C.R. and Walshe, J., 2015. Attitudes to genetically modified food over time: How trust in organizations and the media cycle predict support. Public Understanding of Science, 24: 601-618.

McFarlane, B. L., and Boxall, P. C., 2000. Factors influencing forest values and attitudes of two stakeholder groups: The case of the Foothills Model Forest, Alberta, Canada. Society \& Natural Resources, 13: 649-661.

Mistik forest management agreement area (2013). http://www.mistik.ca/fma.htm.

Natural Resources Canada (2012). The state of Canada's forests: Annual Report 2012.

Natural Resources Canada (2014). The state of Canada's forests: Annual Report 2014

Nelson, C.H., 2001. Risk perception, behavior, and consumer response to genetically modified organisms toward understanding American and European public reaction. American Behavioral Scientist, 44: 1371-1388.

Onyango, B., Govindasamy, R., Hallman, W., Jang, H. and Puduri, V.S., 2006. Consumer acceptance of genetically modified foods in South Korea: Factor and cluster analysis. Journal of Agribusiness, 24: 61.

Peelle, E., 2000. Stakeholder views and concerns about bioenergy: organizational focus, driver issues and uncertainty. In Proceedings, Bioenergy 
Pew Research Centre (2010). https://cbt20.wordpress.com/tag/saskatchewan/

Pin, R.R., and Gutteling, J.M., 2009. The development of public perception research in the genomics field: an empirical analysis of the literature in the field. Sci. Commun. 31: 57-83.

Payn, T., Carnus, J.M., Freer-Smith, P., Kimberley, M., Kollert, W., Liu, S., Orazio, C., Rodriguez, L., Silva, L.N. and Wingfield, M.J., 2015. Changes in planted forests and future global implications. Forest Ecology and Management, 352: 57-67.

Priest, S.H., Bonfadelli, H. and Rusanen, M., 2003. The "trust gap" hypothesis: Predicting support for biotechnology across national cultures as a function of trust in actors. Risk Analysis, 23: 751-766.

Rollins, C., Boxall, P. C., and Luckert, M. K., 2015. Public preferences for planting genetically improved poplars on public land for biofuel production in western. Canadian Journal of Forest Research, 45: 1785-1794.

Rayner, J., McNutt, K. and Wellstead, A., 2013. Dispersed capacity and weak coordination: The challenge of climate change adaptation in Canada's forest policy sector. Review of Policy Research, 30: 66-90.

Sanderson, K., Saunders, C., Nana, G., Stroombergen, A., Campbell, H., Fairweather, J. and Heinemann, A., 2003. Economic risks and opportunities from the release of genetically modified organisms in New Zealand. Ministry for the Environment, Wellington.

Şchiopu, D., 2010. Applying Two-step cluster analysis for identifying bank customers' profile." Buletinul, 62: 66-75.

Schmer, M.R., Vogel, K.P., Mitchell, R.B. and Perrin, R.K., 2008. Net energy of cellulosic ethanol from switch grass. Proceedings of the National Academy of Sciences, 105: 464-469.

Sheehy, H., Legault, M., and Ireland, D., 1998. Consumers and biotechnology: A synopsis of survey and focus group research. Journal of Consumer Policy, 21: 359-386.

Sholdere, J., 2003. The biotechnology communication paradox: Experimental evidence and the need for a new strategy. Journal of Consumer Policy, 26: 125-157.

Siegrist, M., Connor, M. and Keller, C., 2012. Trust, confidence, procedural fairness, outcome fairness, moral conviction, and the acceptance of GM field experiments. Risk Analysis, 32: 1394-1403.

Snow, A.A., Andow, D.A., Gepts, P., Hallerman, E.M., Power, A., Tiedje, J.M. and Wolfenbarger, L.L., 2005. Genetically engineered organisms and the environment: current status and recommendations. Ecological Applications, 15: 377-404.

Tabachnick, B.G., Fidell, L.S. and Osterlind, S.J., 2001. Using multivariate statistics.

Tait, J. D., Bruce, A., and Chataway, J., 2007. OECD International Futures Project on the Bio-economy to 2030: Designing a Policy Agenda. Health Biotechnology to 2030. OECD International Futures Programme.

Tindall, D. B., Ronald, L. T., and Pamela, P., 2013. Aboriginal Peoples and Forest Lands in Canada. Vancouver, British Columbia: UBC Press.

Voss, A.G.J., Spiller, A. and Enneking, U., 2009. Farmer acceptance of genetically modified seeds in Germany: Results of a cluster analysis. International Food and Agribusiness Management Review, 12: 61-80.

White, H., 1980. A heteroskedasticity-consistent covariance matrix estimator and a direct test for heteroskedasticity. Econometrica, 48: 817-838. 
Wieczorek, A., 2003. Use of biotechnology in agriculture: Benefits and risks. Cooperative Extension Service. BIO, 3: 1-6.

Wunderlich, S. and Gatto, K.A., 2015. Consumer Perception of Genetically Modified Organisms and Sources of Information-. Advances in Nutrition, 6: 842-851.

Zechendorf, B., 1994. What the public thinks about biotechnology. Nature Biotechnology, 12: 870-875. 
Figure 1: Example of a hypothetical referendum question (Genome + BF scenario) used to measure public preferences for using different Poplar breeding technologies for use on public land (Source: Rollins et al. 2015)

\begin{tabular}{|c|c|c|}
\hline Policy and Management Features & $\begin{array}{l}\text { Current Policy and Management } \\
\text { Approaches }\end{array}$ & $\begin{array}{l}\text { New Policy and Management } \\
\text { Approaches }\end{array}$ \\
\hline \multicolumn{3}{|l|}{$\begin{array}{l}\text { "Improved" Poplars On Commercial } \\
\text { Public Forest Land in Alberta }\end{array}$} \\
\hline $\begin{array}{l}\text { Region where parent trees are } \\
\text { located }\end{array}$ & $\begin{array}{l}\text { Parent trees come from the same } \\
\text { region as regenerated trees }\end{array}$ & $\begin{array}{l}\text { Parent trees can come from any } \\
\text { location }\end{array}$ \\
\hline Breeding method & $\begin{array}{l}\text { Traditional breeding using observed } \\
\text { traits }\end{array}$ & $\begin{array}{l}\text { Breeding assisted by genetic } \\
\text { information (DNA markers) }\end{array}$ \\
\hline \multicolumn{3}{|l|}{$\begin{array}{l}\text { How commercial public forest land } \\
\text { in Alberta is used }\end{array}$} \\
\hline & $\begin{array}{c}\text { Non-Harvested (40\%) } \\
\text { Harvested Coniferous Trees (40\%) } \\
\text { Harvested Natural Poplars (20\%) } \\
\text { Harvested “Improved” Poplars } \\
\text { (less than 0.1\%) }\end{array}$ & $\begin{array}{l}\text { Non-Harvested (48\%) } \\
\text { Harvested Coniferous Trees (40\%) } \\
\text { Harvested Natural Poplars (9\%) } \\
\text { Harvested "Improved" Poplars (3\%) }\end{array}$ \\
\hline $\begin{array}{l}\text { Impact on forest industry in Alberta } \\
\text { (jobs and income) }\end{array}$ & No change & Moderate positive impact \\
\hline $\begin{array}{l}\text { Reduction in carbon emissions in } \\
\text { Alberta from using poplar biofuels }\end{array}$ & None & $\begin{array}{l}\text { Equivalent to } 120,000 \text { cars off the } \\
\text { road per year in Alberta }\end{array}$ \\
\hline
\end{tabular}

Figure 2: Overall model level quality of clustering

Cluster Quality

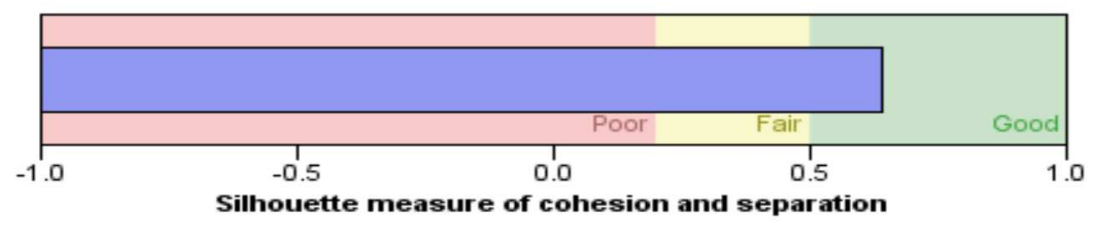


Figure 3: Cluster predictors in each cluster

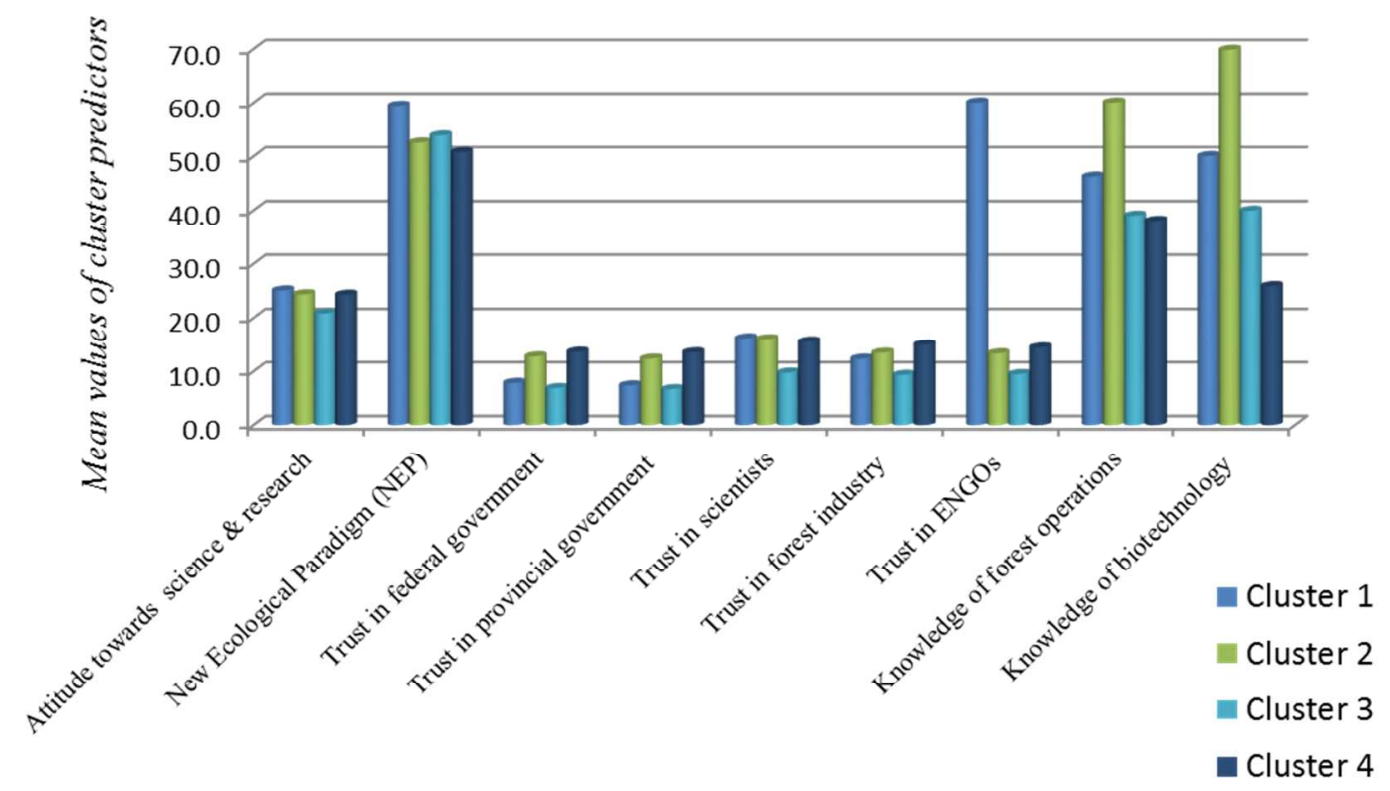


Table 1: Comparison of socio-demographic characteristics between the 2014 sample used for this study (N) and 2011 Canada census data (Pop.) for Alberta, British Columbia, Manitoba, and Saskatchewan.

\section{Province}

\begin{tabular}{|c|c|c|c|c|c|c|c|c|}
\hline \multirow[b]{2}{*}{ Characteristics } & \multicolumn{2}{|c|}{ Alberta } & \multicolumn{2}{|c|}{ British Columbia } & \multicolumn{2}{|c|}{ Manitoba } & \multicolumn{2}{|c|}{ Saskatchewan } \\
\hline & $\mathrm{N}$ & Pop. & $\mathrm{N}$ & Pop. & $\mathrm{N}$ & Pop. & $\mathrm{N}$ & Pop. \\
\hline Number of respondents & 1205 & - & 1249 & - & 502 & - & 500 & - \\
\hline Male (\%) & 42 & 51 & 44 & 49 & 42 & 49 & 40 & 50 \\
\hline Average age $(18+)$ & 48 & 45 & 49 & 48 & 50 & 47 & 50 & 47 \\
\hline \multicolumn{9}{|l|}{$\begin{array}{l}\text { Population of Centre of } \\
\text { residence }(\%)\end{array}$} \\
\hline$>100,000$ & 57 & 68 & 51 & 68 & 58 & 60 & 49 & 46 \\
\hline $10,000-100,000$ & 22 & 13 & 31 & 19 & 13 & 8 & 16 & 20 \\
\hline$<10,000$ & 21 & 18 & 18 & 12 & 29 & 32 & 35 & 34 \\
\hline $\begin{array}{l}\text { Post-secondary education } \\
\text { attained }(\%)\end{array}$ & 67 & 55 & 61 & 56 & 60 & 47 & 59 & 47 \\
\hline
\end{tabular}

Source: Education data from Statistics Canada (2012b); all other data from Statistics Canada (2012a). 
Table 2: The number and percentages of respondents in each cluster

\begin{tabular}{|c|c|c|c|c|c|}
\hline Variables & & & Cluster & & \\
\hline & Environmentalists & Knowledgeable & Challengers & Supporters & Total \\
\hline Number of Respondents & 1,079 & 1,056 & 439 & 882 & 3,456 \\
\hline Percentage of total sample & 31.2 & 30.6 & 12.7 & 25.5 & 100 \\
\hline Rural dwellers & 340 & 292 & 149 & 294 & 1,075 \\
\hline Urban dwellers & 739 & 764 & 290 & 588 & 2,381 \\
\hline Number of farmers & 40 & 66 & 14 & 33 & 153 \\
\hline Non-farm & 1,039 & 990 & 425 & 849 & 3,303 \\
\hline Albertans (\%) & 29.8 & 41.6 & 17 & 34.2 & 30.6 \\
\hline British Columbians (\%) & 41.6 & 23.7 & 34.4 & 15.7 & 28.8 \\
\hline Manitobans (\%) & 16.1 & 3.2 & 38.2 & 11.1 & 19.7 \\
\hline Saskatchewanians (\%) & 12.5 & 21.5 & 10.4 & 39 & 20.9 \\
\hline
\end{tabular}

Notes: The response rate is sufficient in the sense that all participants have provided answers to each question 
Table 3: A summary of mean values of clustering factors used in defining clusters

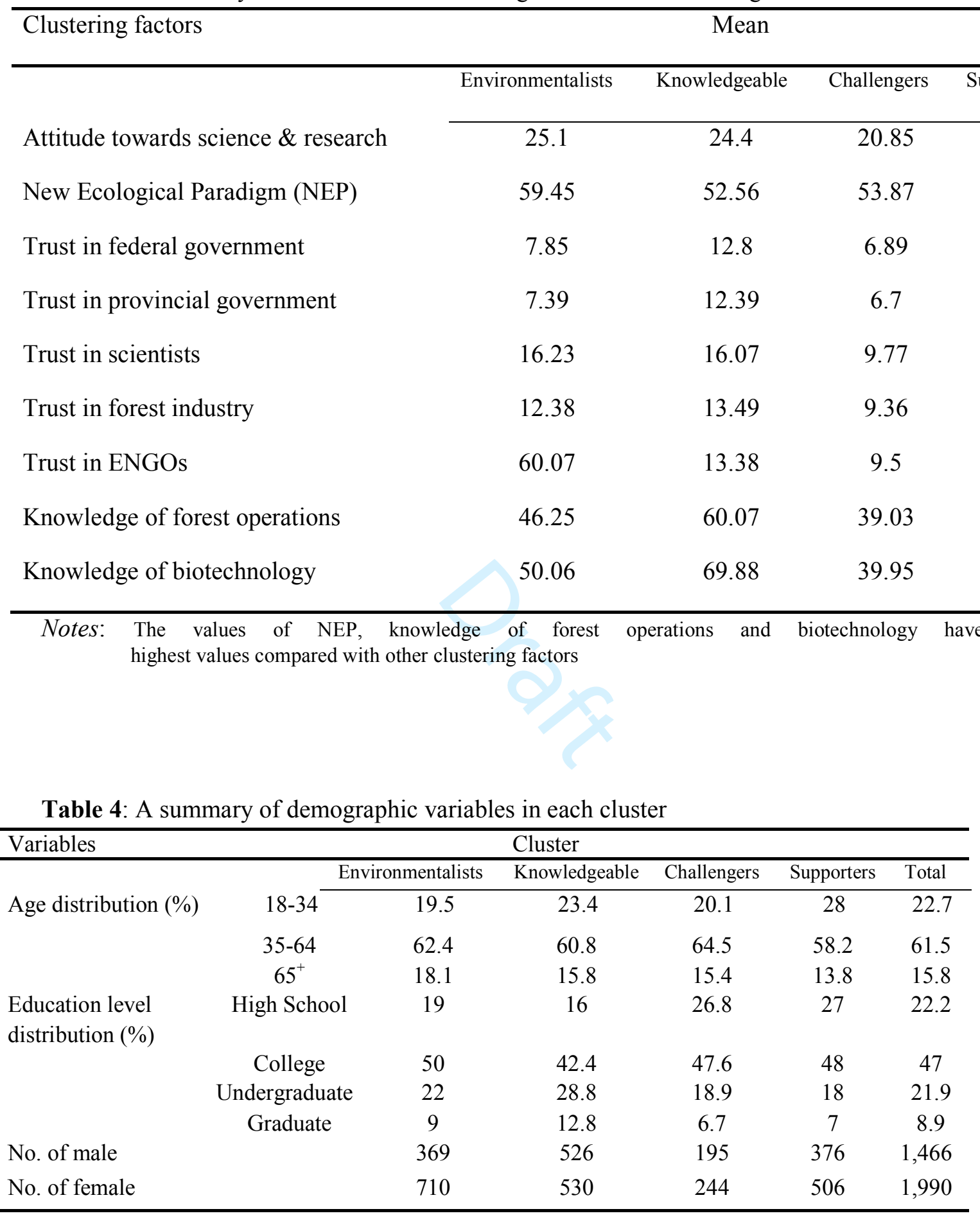


Table 5: Relative percentage of vote in support of new forest policy alternatives in each cluster

\begin{tabular}{lcccc}
\hline Policy alternatives & \multicolumn{3}{c}{ Relative percentage of votes } \\
\hline & Environmentalists & Knowledgeable & Challengers & Supporters \\
\cline { 2 - 5 } $\begin{array}{l}\text { Vote for tradition breeding } \\
\text { (excluded) }\end{array}$ & & & & \\
Vote for DNA breeding (\%) & 40.22 & 50.38 & 40.09 & 50.11 \\
Vote for genetic modification (\%) & 39.57 & 47.50 & 37.29 & 51.53 \\
Vote for biofuel (\%) & 53.39 & 61.14 & 42.52 & 59.45 \\
\hline
\end{tabular}

Table 6: Description of dependent and independent variables

Variable name Descriptions

\section{Dependent variable:}

Vote

Independent variables:

Traditional breeding (TB)

DNA breeding (DNA)

Genetic modification (GM)

Biofuel production (BF)
1 if respondent in cluster ' $c$ ' chooses the new policy; 0 else

$$
\begin{aligned}
& 1 \text { if respondent in cluster 'c' chooses TB; } 0 \text { else } \\
& 1 \text { if respondent in cluster ' } c \text { ' chooses DNA; } 0 \text { else } \\
& 1 \text { if respondent in cluster ' } c \text { ' chooses GM; } 0 \text { else } \\
& 1 \text { if respondent in cluster 'c' chooses BF; } 0 \text { else }
\end{aligned}
$$


Table 7: A summary of marginal effects from probit model estimates in each cluster in terms of a percent change in the probability of voting to support a new policy with a one unit change in the variable.

\begin{tabular}{lcccc}
\hline Variables & \multicolumn{3}{c}{ Cluster } \\
\hline & Environmentalists & Knowledgeable & Challengers & Supporters \\
\cline { 2 - 4 } DNA & $-3.2^{* *}$ & $1.7^{* *}$ & $-3.6^{* *}$ & $0.4^{* *}$ \\
$\mathrm{GM}$ & $-1.6^{*}$ & $-6.1^{*}$ & $-5.1^{* *}$ & $2.7^{* *}$ \\
$\mathrm{BF}$ & $34.2^{*}$ & $38.4^{*}$ & $-27.5^{* *}$ & $29.3^{*}$ \\
$\mathrm{~TB}^{+}$ & & & & \\
\hline
\end{tabular}

\footnotetext{
Notes: $" \&{ }^{* *}$ denote statistical significant at the $5 \%$ and $10 \%$ levels respectively. ${ }^{+}$denotes traditional breeding without biofuel production is considered as the base scenario. All values are given in $\%$.
} 